\title{
Levantamento e análise das principais condicionantes da percepção de segurança na sociedade brasileira e proposta de um modelo de atuação para a PMSE
}

O presente trabalho abordou a importância de se considerar a sensação de (in)segurança sentida pela população, como base na formulação de políticas de segurança pública voltadas ao exercício pleno da cidadania. Para isso, buscou-se na literatura as principais contribuições de autores acerca dos principais condicionantes que influenciam na percepção de segurança por parte do indivíduo, bem como os fatores que o colocam em exposição ao risco. Na discussão sobre violência e criminalidade, diversos condicionantes foram apontados como importantes para a compreensão dos níveis de sensação de insegurança, tais como: 0 aumento da criminalidade; a influência dos meios de comunicação; e atributos do próprio indivíduos, tais como: cor, gênero, renda, idade, dentre outras características sociodemográficas. Foram utilizados como material empírico os dados da Pesquisa Nacional por Amostra de Domicílios - PNAD (2009) e da Pesquisa de vitimização realizada pela SENASP, publicada em 2017, dando-se um enfoque maior aos índices do estado de Sergipe, traçando-se um ligeiro comparativo com a média nacional. Ao final do estudo foi traçada uma matriz SWOT da Polícia Militar do Estado de Sergipe, a partir da qual foram propostas políticas de segurança pública com os objetivos de, através das atividades de policiamento ostensivo, buscar reduzir a insegurança junto à população sergipana.

\section{Survey and analysis of the main constraints of the perception of security in Brazilian society and proposal of a performance model for PMSE}

\begin{abstract}
The present work addressed the importance of considering the sense of (un) security felt by the population, as a basis for the formulation of public security policies aimed at the full exercise of citizenship. For this, we searched in the literature the main contributions of authors about the main conditions that influence the perception of safety by the individual, as well as the factors that put him at risk exposure. In the discussion about violence and criminality, several conditions were pointed as important for understanding the levels of insecurity sensation, such as: the increase of crime; the influence of the media; and attributes of the individuals themselves, such as color, gender, income, age, among other sociodemographic characteristics. The data from the National Household Sample Survey - PNAD (2009) and from the SENASP Victimization Survey, published in 2017, were used as empirical material, giving a greater focus to the Sergipe State indices, tracing a slight comparative with the national average. At the end of the study, a SWOT matrix of the Sergipe State Military Police was drawn up, from which public security policies were proposed with the objective of, through the activities of overt policing, to seek to reduce insecurity among the people of Sergipe.
\end{abstract}

Keywords: Public safety policies; Ostentatious policing; Security perception; Victimization.

Topic: Gestão Pública

Reviewed anonymously in the process of blind peer
Received: 07/04/2019

Approved: 10/06/2019
Jefferson Roberto Menezes de Souza

Escola Judicial do Estado de Sergipe, Brasil

http://lattes.cnpq.br/465550406603178

jefferson.souza2@pm.se.gov.br

Carlos Eduardo Silva (iD

Companhia Brasileira de Produção Científica, Brasil

http://lattes.cnpq.br/3700554054159220

http://orcid.org/0000-0001-8358-0263

carlos.eduardo@cbpciencia.com.br
Referencing this:

SOUZA, J. R. M.; SILVA, C. E.. Levantamento e análise das principais condicionantes da percepção de segurança na sociedade brasileira e proposta de um modelo de atuação para a PMSE. Revista Brasileira de Administração Científica, v.10, n.2, p.74-93, 2019. DOI: http://doi.org/10.6008/CBPC2179-684X.2019.002.0006 
Levantamento e análise das principais condicionantes da percepção de segurança na sociedade brasileira e proposta de um modelo de atuação para a PMSE

\section{INTRODUÇÃO}

Com o advento da Revolução Industrial, o modelo de produção capitalista passou a demandar um volume maior de mão de obra, ocasionando um inchaço populacional nas cidades, promovido pela chegada, em massa, de imigrantes em busca de oportunidades. Porém, por não estar preparada estruturalmente para acomodá-los, essa dinâmica transformou a cidade num ambiente hostil que terminou por gerar um aumento efetivo nos índices de criminalidade, acompanhado de um aumento na sensação de insegurança.

Nas últimas três décadas, têm-se observado um crescimento da literatura internacional que aborda a insegurança com relação ao crime, bem como as formas de combatê-la. Dentre as razões para esse comportamento, é possível citar a maior disponibilidade de dados, bem como suas consequências para a economia e o bem-estar da sociedade (PLASSA et al., 2016). Nesse contexto, Soares (2008) alerta que a sensação de insegurança é muito alta no Brasil, o suficiente para ser considerada uma questão de saúde mental pública, fato este que denota a relevância em se desenvolver políticas públicas no intuito de reduzila, porém o autor ressalta que, antes, é preciso conhecer melhor o fenômeno e seus determinantes.

Em 2016, o Brasil alcançou a incrível marca de 62.517 homicídios, de acordo com os dados do Ministério da Saúde (MS). Estes índices equivalem a uma taxa de 30,3 mortes para cada 100 mil habitantes, o que corresponde a 30 vezes a taxa da Europa. Dados apontam que, só nos últimos dez anos, 553 mil pessoas foram a óbito, devido à violência intencional no Brasil (CERQUEIRA et al., 2018).

Dados extraídos do Relatório Mundial de Prevenção da Violência em 2014, conduzido pela Organização Mundial da Saúde (OMS), para 2012, apontam que o Brasil apresentava uma taxa de homicídios de 32,4 para cada 100 mil habitantes, totalizando, em números gerais, 50.108 mil homicídios, somente naquele ano. Com esse quadro, o Brasil figura entre os 15 países (do total de 133) mais violentos do mundo.

No Brasil, o primeiro passo para a elaboração de uma pesquisa de alcance nacional foi dado pelo Instituto Brasileiro de Geografia e Estatística (IBGE) através da Pesquisa Nacional por Amostra de Domicílio (PNAD) em sua edição de 1988. Porém, só em 2009 a referida pesquisa adicionou a sensação de segurança aos tópicos pesquisados. Após essa iniciativa, a maior parte das pesquisas sobre vitimização concentrou-se na região Sudeste (São Paulo, Rio de Janeiro e Minas Gerais) com especial destaque ao Rio de Janeiro (CATÃO, 2008).

Apesar da relevância das pesquisas de vitimização, seus dados serão utilizados para identificar outras questões, ainda pouco estudadas no ambiente acadêmico, e que se referem à percepção das vítimas sobre o risco em diferentes níveis geográficos utilizando-se, para isso, o material empírico dos dados levantados pelo IBGE em sua segunda PNAD.

Desta forma, observa-se que, tanto a vitimização, quanto a percepção sobre a segurança, podem ser concebidas como indicadores adequados e de bastante relevância para a formulação, gestão e avaliação de políticas públicas voltadas ao policiamento ostensivo, bem como para identificar o grau de confiança da população no tocante às instituições policiais. 
Levantamento e análise das principais condicionantes da percepção de segurança na sociedade brasileira e proposta de um modelo de atuação para a PMSE

\section{METODOLOGIA}

Para a realização do presente artigo utilizou-se do método tipológico, para se obter uma visão geral da temática, através da técnica de pesquisa bibliográfica e exploratória. A pesquisa foi organizada em tópicos, sendo o primeiro destinado à introdução do tema, onde será apresento o objeto de estudo; O segundo tópico trata do desenvolvimento que divide-se em subtópicos, sendo o primeiro deles destinado aos conceitos de segurança pública, violência e criminalidade; O segundo subtópico abordará algumas considerações necessárias sobre sensação de (in)segurança, medo e vitimização, bem como suas relações com a criminalidade.

O terceiro subtópico tratará do Policiamento Ostensivo como forma de redução da criminalidade, dando-se ênfase ao papel institucional das Corporações Policiais Militares na redução da criminalidade, bem como os entraves por elas enfrentados; O quarto subtópico será destinado à coleta de dados da pesquisa do PNAD-2009 e dos Estudos sobre vitimização BRASIL (2017), onde será dado ênfase aos dados pertinentes ao Estado de Sergipe; O quinto e último subtópico do desenvolvimento destinar-se-á ao estudo de políticas de segurança pública orientadas à resolução do problema por meio de ações estratégicas, com foco nas ações da Polícia Militar; O terceiro e último tópico tratará das conclusões acerca do estudo realizado.

Dessa forma, o presente trabalho tem o propósito de relacionar e analisar os principais condicionantes individuais e sociais disponíveis na literatura que influenciam na percepção de (in)segurança dos brasileiros, e, através dos dados obtidos no IBGE (2009) e nos Estudos de Vitimização BRASIL (2017), relativos ao Estado de Sergipe, propor linhas de ação que podem ser adotadas pela Polícia Militar do Estado de Sergipe de modo a reduzir em consonância com sua missão constitucional, de forma a atuar reduzindo a sensação de (in)segurança dos sergipanos e, consequentemente, os Índices de Criminalidade no Estado.

\section{DISCUSSÃO TEÓRICA}

\section{Segurança pública, violência e criminalidade}

A Constituição Federal de 1988, além de assegurar o direito à segurança como direito individual fundamental, definindo-o no caput do Art. 5으, e também como direito social, conforme o caput do Art. 6으, traz um capítulo intitulado 'Da segurança pública', composto pelo Art. 144, o qual dispõe que: 'A segurança pública, dever do Estado, direito e responsabilidade de todos, é exercida para a preservação da ordem pública e da incolumidade das pessoas e do patrimônio'.

A definição acima sinaliza para o fato de que a segurança pública não pode ser vista, unicamente, como uma atribuição do Estado, posto que a sociedade também possui papel de relevância, não apenas no tocante à participação e controle das políticas implementadas, mas também na socialização das pessoas, nos mecanismos de controle social, a partir da premissa de que não é somente o controle pelo Estado que garante a segurança, de uma forma geral (FERREIRA et al., 2011).

É importante salientar que, ao ser definida como uma atividade que possui como objetivo final a garantia da ordem pública, o conceito de segurança pública relaciona-se com o de ordem pública, pois a 
Levantamento e análise das principais condicionantes da percepção de segurança na sociedade brasileira e proposta de um modelo de atuação para a PMSE

garantia desta, consiste no objeto daquela (VILARDI, 2010). Desta forma, é importante acrescentar o pensamento de Rodrigues (2009) sobre a ordem pública que, mais do que a ausência de perturbações à segurança e tranquilidade, limitando-se à obediência, sem ressalvas, à ordem nas ruas, no contexto atual consiste em tudo aquilo que se relaciona com a preservação da estrutura social, dentro de padrões mínimos de segurança e tranquilidade, onde os cidadãos podem exercer seus direitos e liberdades sem qualquer tipo de constrangimento indevido.

Fontoura et al. (2009) alerta para o fato de que o capítulo da Constituição Federal, destinado à segurança pública, trata apenas de órgãos de natureza policial, não incorporando atores importantes como o Ministério Público, o Poder Judiciário ou os agentes prisionais neste campo de atuação do Estado. Isto só vem comprovar a visão de uma segurança com foco na repressão policial, que se apresenta como limitada e produtora de políticas pouco eficientes que terminam por favorecer o aumento da violência.

No Brasil, a violência está no centro das atenções, fazendo parte do dia a dia da população local, ocupando posição de destaque nos noticiários. Ao ser tema recorrente em programas de tv, passa a povoar a mente humana de forma ameaçadora, causando um profundo sentimento de insegurança. Para Chesnais (1999), essa evolução consiste num sintoma de desintegração social, mal-estar coletivo e desregramento das instituições públicas.

Neste contexto, a violência, sobretudo urbana, passa a ser responsável por diversos transtornos psicológicos, diante das inúmeras situações vividas nos grandes centros urbanos, as quais afetam tanto as pessoas que as vivenciam, quanto as que se sentem na iminência de vivenciá-las. Desta forma, o medo e o sentimento de insegurança passam a guardar estreita relação com os casos de homicídios, assaltos, sequestros, dentre outros atos violentos com motivação de gênero, religião, raça, dentre outros fatores (LOPES, 2014).

É pertinente salientar o pensamento de Lima Neto et al. (2014) ao destacar que o crime é um fenômeno de grande complexidade que se integra à sociedade, e cujo aumento guarda relação com os aspectos sociais, institucionais e o ambiente físico. Diante disto, Hipólito et al. (2012) afirma que, no tocante à complexidade dos fatores do crime, a sua ocorrência está relacionada à presença de três elementos, denominados pelos criminologistas de triângulo do crime, a saber: um infrator, um alvo vulnerável e um ambiente favorável à ação criminosa.

Na visão de Cerqueira et al. (2018), o crime é fruto de uma série de fatores que compreendem não apenas o sistema de justiça criminal e as características idiossincráticas dos indivíduos, mas também circunstâncias relacionadas à educação e acompanhamento de crianças e jovens, aliados à falta de oportunidade de acesso a determinados bens econômicos e, em última instância, a um exercício pleno dos direitos de cidadania. Deste modo, o problema da delinquência e criminalidade teria uma origem transversal e exigiria o emprego de ações intersetoriais coordenadas que percorre as áreas de saúde, educação, cultura, habitação, mercado de trabalho, esportes, dentre outras. 
Levantamento e análise das principais condicionantes da percepção de segurança na sociedade brasileira e proposta de um modelo de atuação

Analisando-se a evolução dos índices de homicídio no Brasil na última década, verifica-se uma grande heterogeneidade entre os Estados, pelo que se observam variações nas taxas de $-56 \%$, como ocorreu com o Estado de São Paulo, a $+256,9 \%$, no Estado do Rio Grande do Norte. Os dados revelam que a situação é particularmente grave nos Estados do Norte e Nordeste, os quais guardam as maiores taxas de homicídios por 100 mil habitantes, estando Sergipe situado no topo do ranking $(64,7)$, seguido de Alagoas $(54,2)$, Rio Grande do Norte $(53,4)$, Pará $(50,8)$, Amapá $(48,7)$, Pernambuco $(47,3)$ e Bahia $(46,9)$.

Soares (2006) ressalta que as explicações para a violência e a criminalidade não são fáceis e, neste sentido, é preciso tomar muito cuidado para não cair na armadilha das generalizações. Soares (2006) defende ainda que o crime não existe de forma singular e, neste contexto, existem diversas práticas criminosas que estão associadas a dinâmicas sociais bem diferentes. Desta forma, não se pode pensar na identificação de uma única causa para este fenômeno, diante do universo heterogêneo da criminalidade.

Toda esta problemática passa a assumir proporções ainda maiores quando o aumento da violência e criminalidade no país conduz o Estado, juntamente aos órgãos de segurança pública, de justiça criminal e a sociedade organizada, a perceber que o controle da criminalidade não deve estar focado, unicamente, em ações repressivas de polícia, mas deve perpassar o policiamento tradicional, buscando ações efetivas de prevenção as quais atuem diretamente nas causas, fomentando e fortalecendo parcerias com outros órgãos da administração pública, bem como profissionais de outras áreas do conhecimento, como arquitetura, urbanismo, engenharia, tecnologia, psicologia, dentre outras, em busca da paz social (LIMA NETO et al., 2014).

\section{Sensação de (in)segurança, medo e vitimização: algumas considerações necessárias}

Etimologicamente, pode-se dizer que medo significa inquietação diante de um perigo real ou apenas imaginário, de pavor diante de determinadas situações (FERREIRA et al., 2011). O medo do crime é um sentimento muito recorrente na atualidade e reflete a angústia individual que, muitas vezes, é expandida à comunidade, de um modo geral, em virtude do fenômeno da criminalidade que cresce, a cada dia, aparentemente fora do controle, e do estado coletivo de insegurança que dele pode passar a decorrer (DANTAS et al., 2007). Porém, ele passa a se tornar algo doentio quando se traduz numa angústia demasiada e injustificada, caracterizada pela falta de correlação direta com o perigo propriamente dito, ou sua ameaça, num dado período.

É certo que algum grau de insegurança é saudável, sob o ponto de vista pessoal e, até mesmo, coletivo, pois o excesso de segurança pode levar o indivíduo a deixar de tomar precauções necessárias, tais como travar as portas do carro, manter um olhar atento ao seu redor, dentre outras situações que, em conjunto, podem culminar num aumento da criminalidade, pois boa parte da prevenção ao crime passa pelo comportamento preventivo das vítimas em potencial, da mesma forma que, no corpo humano, o medo e a dor, na medida certa, podem ser fatores de proteção à vida do indivíduo. 
Levantamento e análise das principais condicionantes da percepção de segurança na sociedade brasileira e proposta de um modelo de atuação

Por outro lado, insegurança em excesso traz consequências ruins, tais como: desvalorização de imóveis, empresas deixam de instalar-se em locais inseguros, turistas deixam de visitar esses locais, as pessoas mudam seus hábitos, deixam de passear à noite, além de interferir na qualidade de vida. Dessa forma, tanto a ausência quanto a presença exagerada do medo trazem custos elevados para a sociedade (BRASIL, 2017).

Na visão de Soares (2008), a sensação de (in)segurança é muito alta no Brasil, a ponto de ser considerada um problema de saúde pública. $O$ autor salienta que seria esperado que pessoas que moram em regiões com elevadas taxas de criminalidade e violência apresentassem maiores níveis de insegurança. Porém, pesquisas apontam que esta relação não ocorre de forma tão intuitiva como se imagina, pois o número de pessoas que afirmam sentir-se inseguras é maior que o quantitativo de indivíduos vitimados pela violência, indicando que o sentimento de insegurança não relaciona-se apenas com situações concretas, como número de assaltos, arrombamentos etc., mas também com questões subjetivas, como influência da mídia, dos vizinhos, percepção dos riscos, ambiente geográfico etc..

Para analisar essas situações, Soares (2008) faz alusão a três dimensões teóricas. A primeira delas é definida como "percepção e informação sobre a violência", teoria segundo a qual faz-se necessário que a informação chegue ao indivíduo para que ele venha a sentir medo e insegurança; A segunda dimensão apontada seria a já difundida "teoria das janelas quebradas" que sugere o princípio de que o crime começa pequeno e termina grande.

Esta teoria guarda relação com a dimensão dos ambientes públicos, os quais ficariam restritos a determinados espaços e horários que, na medida em que vão se desvalorizando e sendo abandonados pela iniciativa pública, acabam se transformando em "não lugares", ou seja, espaços apropriados à ocorrência de delitos. A este conceito, o autor acrescenta a "tese das incivilidades" que consiste em atos como pichações, urinar em público, mau cheiro nas ruas, pessoas morando nas ruas, bem como invasões a prédios públicos abandonados, dando a impressão do descaso com o poder público (SOARES, 2008).

Por último, a terceira dimensão teórica, abordada por Soares (2008), refere-se à questão da "familiaridade" que o indivíduo possui com o medo e o sentimento de (in)segurança. De acordo com essa teoria, as pessoas sentem-se mais seguras em locais conhecidos. Além disso, ela nos afirma que o medo e a insegurança podem ser descritos a partir de áreas concêntricas: quanto mais distante de pontos conhecidos, maior a insegurança e medo.

Embora muitos façam um certo tipo de confusão, existem importantes diferenças entre a Teoria das Janelas Quebradas e o Programa Tolerância Zero. O foco não é o mesmo: enquanto a Teoria das Janelas Quebradas se dirige às comunidades, o programa Tolerância Zero é voltado às pessoas. O programa Tolerância Zero baseia-se em três princípios tradicionais da ciência policial: dispersão pela forte presença policial; o patrulhamento intenso das áreas quentes; e prisões focalizadas, a partir do princípio de que um número relativamente pequeno de criminosos é responsável por uma percentagem bastante alta dos crimes (SOARES, 2008). 
Levantamento e análise das principais condicionantes da percepção de segurança na sociedade brasileira e proposta de um modelo de atuação

Outra variável encontrada para a análise das condicionantes da percepção de segurança entre os indivíduos foi o estado civil. Na literatura que aborda os estilos de vida e vitimização, nota-se que existem diferenças entre os hábitos das pessoas solteiras e das casadas. Estas passam mais tempo com suas famílias em seus domicílios do que as solteiras, o que as impede de passar maior tempo em espaços públicos em contato com pessoas desconhecidas, o que as torna menos vulneráveis à vitimização (BEATO, 2004).

Para Lopes (2014) diante das notícias veiculadas em jornais de grande circulação escritos, falados ou televisionados, que, rapidamente, ganham as conversas informais, já seria esperado o aumento do sentimento de medo do crime pela sociedade, pois situações que seriam impensáveis, num passado próximo, passaram a fazer parte do cotidiano do cidadão brasileiro. Desta forma, Lopes (2014) alerta que a mídia ocupa um papel fundamental ao divulgar os fatos relacionados ao crime, pois direcionam as pessoas a um sentimento de risco a que todos, supostamente, estariam submetidos.

Neste contexto, não se pede que os meios de comunicação, no intuito de reduzir esta lacuna entre a criminalidade real e a percebida, deixem de mostrar os casos de grande comoção, mas que, tão somente, busquem contextualizá-los num cenário mais abrangente e esclarecedor. O pior prejuízo gerado pela disparidade entre a criminalidade real e a percepção de segurança pode ser a adoção de políticas de segurança pública equivocadas, bem como o abandono de outras políticas que estão dando certo, mas não têm o reconhecimento da sociedade. É possível citar a 'legislação do medo' que, tantas vezes, é passada às pressas em momentos de grande comoção social diante de crimes violentos, como a chamada lei Glória Peres no Brasil (BRASIL, 2017).

Fraga (2015) destaca que o medo não pode ser confundido com a percepção de segurança, pois aquele consiste numa abordagem mais emocional, enquanto a percepção de segurança estaria mais voltada ao risco percebido pelo indivíduo. Neste diapasão, questionamentos postos em pesquisas como: ‘Quão seguro é seu bairro?' Ou se o indivíduo se sente seguro andando sozinho no bairro, consistem em exemplos de mensuração da percepção de risco. Porém, quando são solicitados a responder se têm medo de se tornarem vítimas de estupro/roubo/homicídio, representaria uma declaração mais pessoal de preocupação com o crime, baseada em argumentos de grande teor emocional. Fraga (2015) acrescenta que, para caracterização dos conceitos de percepção de risco e medo, nem sempre a literatura, que é bastante extensa, distingue claramente um termo do outro, tratando-os, muitas vezes, como sinônimos.

Soares (2006) traz uma contribuição importante ao ressaltar que, em segurança pública, as consequências tornam-se as causas do próximo movimento, dentro de um ciclo social: determinadas condições favorecem a prática de atos ilícitos os quais terminam por afastar a instalação de empresas, promovendo um aumento nos índices de desemprego, ampliando as condições para o crescimento de certas formas de criminalidade. E o ciclo volta a ter início, em torno do mesmo eixo.

Soares (2006) defende que o contrário também é válido pois se existir uma redução dos índices de criminalidade, bem como da violência existente, criar-se-ia um ambiente favorável à fixação de empresas, 
Levantamento e análise das principais condicionantes da percepção de segurança na sociedade brasileira e proposta de um modelo de atuação para a PMSE

SOUZA, J. R. M.; SILVA, C. E.

ocasionando um aumento da oferta de emprego, melhoria das condições sanitárias e urbanas, e assim sucessivamente.

\section{O Policiamento Ostensivo como redutor da criminalidade e promotor do sentimento de segurança}

Desde o século XIX, nossas polícias são organizadas de maneira dualizada. Após a promulgação da República, as forças policiais militarizadas, que tinham por missão manter a ordem pública, receberam o nome de forças públicas. A elas, sucedeu-se a criação de guardas civis, que passaram a executar o policiamento ostensivo, com objetivo de prevenir a criminalidade (FONTOURA et al., 2009). De acordo com Bretas (1997),

(...) a função de polícia dividiu-se, sem obedecer a um padrão definido, em duas forças paralelas: a polícia civil e a polícia militar. A polícia civil originou-se da administração local, com pequenas funções judiciárias, ao passo que a polícia militar nasceu do papel militar do patrulhamento uniformizado de rua. Com o tempo, a polícia civil teve suas funções administrativas e judiciais restringidas, enquanto a polícia militar sofria frequentes ataques como inadequada para o policiamento diário, motivando a criação de outras polícias uniformizadas concorrentes, principalmente a Guarda Civil.

No Brasil, a gravidade dos problemas relacionados à criminalidade, violência, e segurança pública promovem debates os quais, frequentemente, são direcionados para a necessidade de uma reforma institucional do sistema policial, colocando em voga a defesa, muitas vezes demagógica por parte de alguns políticos, da unificação das polícias (AZEVEDO, 2003).

Azevedo (2003) aponta que os sistemas de informações, aliados aos dados estatísticos de ocorrências, bem como sua localização espacial (geoprocessamento), são indispensáveis para a identificação dos padrões de criminalidade possibilitando uma melhor avaliação das percepções sociais da violência, conferindo maior eficiência às ações de policiamento, a partir do momento que favorece a identificação de agressores, a avaliação da incidência sobre diferentes grupos sociais, o relacionamento entre agressor e vítima, dentre outros fatores.

Azevedo (2003) afirma que, em diversas situações, não existe a presença obrigatória de um criminoso, mas de um conflito social ou mesmo um sentimento de insatisfação entre as partes, o qual demanda a intervenção da polícia que atuará como solucionadora do conflito buscando sempre o reequilíbrio. Observa-se que a perspectiva é mais voltada à negociação com o objetivo de se chegar a um acordo, do que a uma ação punitiva, denotando um foco na transformação social. O conhecimento empírico revela que esse novo modelo requer uma mudança, de ordem cultural, significativa, de cunho organizacional, principalmente no tocante à descentralização de decisões, reflexão sobre o verdadeiro papel da polícia, maior autonomia para os agentes que, neste caso estariam mais voltados à população que ao próprio Estado.

Na visão de Soares (2003) o quadro de insegurança, por que passa o Brasil é gravíssimo, por diversas razões dentre as quais podemos apontar: a magnitude das taxas de criminalidade e a intensidade da violência envolvida nelas; a exclusão de setores da sociedade brasileira, que permanecem sem acesso aos benefícios mais elementares, proporcionados pelo Estado Democrático de Direito, tais como liberdade de expressão e organização e o direito trivial de ir e vir; e a degradação institucional a que se tem atrelado o crescimento da 
Levantamento e análise das principais condicionantes da percepção de segurança na sociedade brasileira e proposta de um modelo de atuação

criminalidade: o crime, cada vez mais está se organizando e adentrando às instituições públicas, corrompendo-as, e às práticas policiais continuam marcadas pelas distinções de classe, cor e sexo.

Para Cerqueira et al. (2018), as experiências bem sucedidas de redução da criminalidade violenta, devem-se à repressão qualificada, através do emprego da inteligência policial preventiva e investigativa, respeitando-se os direitos dos cidadãos e conjugada com programas e ações preventivas no campo social, focalizadas em bairros e locais cuja população é mais vulnerável socioeconomicamente e onde se encontram as maiores incidências de crimes violentos.

Os organizadores acrescentam que essa nova estratégia se afastou da crença, que porventura nunca foi confirmada, de que se poderia conseguir melhores resultados na segurança pública através de um maior rigor nas leis e encarceramento em massa, principalmente de jovens, negros e de indivíduos com baixo grau de escolaridade. Esse encarceramento teria sido responsável pelo aumento de mais de $1.000 \%$ no número de detentos no sistema carcerário de todo o país desde 1980 (CERQUEIRA, 2013), e pressionou o orçamento público, sem que se tivesse qualquer impacto perceptível na evolução da criminalidade, ao mesmo tempo que o número de homicídios cresceu $258 \%$.

Dessa forma, chega-se a um entendimento de que mais importante que o aprisionamento em massa, de baixa qualidade, na base do policiamento ostensivo, são os aprisionamentos de maior qualidade, que consiste na retirada das ruas dos homicidas contumazes, bem como os líderes do tráfico, que só são presos diante de um trabalho prévio e coordenador de inteligência policial.

Frente a esse contexto, as políticas preventivas, que não contemplam mudanças estruturais, tornamse superficiais e não tem uma ação efetiva na resolução do problema que se deseja evitar. Porém, elas salvam vidas e reduzem sofrimentos e danos, promovendo o bem-estar social. Quando isso acontece, as políticas de cunho preventivo promovem padrões de comportamento, gerando sentimentos e ocasionando percepções coletivas que são convertidas em causas de situações menos suscetíveis às pressões dos fatores criminógenos. De forma metafórica, os sintomas apresentam potencial letal para o paciente e devem ser tratados enquanto o paciente não for submetido à cirurgia, pois, sem tratá-los, a cirurgia não será possível (SOARES, 2006).

Um sério problema enfrentado pelo policiamento ostensivo na execução de sua missão constitucional consiste na carência de efetivo. A SENASP entende que uma polícia com menor efetivo, mas qualificada e mais bem preparada em termos de recursos físicos, deve ser mais bem avaliada pela sociedade, sem comprometer a sua eficiência e eficácia. A qualificação estaria vinculada basicamente ao tempo de formação, ao investimento em recursos tecnológicos e materiais, bem como ao acesso às especialidades, ao aprimoramento técnico-profissional, ao controle administrativo dentre outros.

Conforto (1998) descreveu o Sistema Norte Americano de cálculo de efetivo, explicando que tal sistema é originário de profunda análise estatística e científica por técnicos americanos, os quais chegaram a um consenso de que o efetivo necessário para o sistema policial local, varia entre 1,5 (um e meio) e 2,5 (dois e meio) policiais para cada 1.000 (mil) habitantes, tanto na área urbana como na área rural. Nesta 
Levantamento e análise das principais condicionantes da percepção de segurança na sociedade brasileira e proposta de um modelo de atuação para a PMSE

variação estão inseridos os fatores criminológicos, os quais podem mudar, de local para local, aumentando ou diminuindo os índices de criminalidade. Conforto (1998) aponta os seguintes os fatores criminológicos, que implicam na ampliação ou redução de efetivos nas localidades portuária, de fronteira, de jogos e diversões, de população flutuante e de baixa renda per capita.

\begin{abstract}
As localidades portuárias são os aglomerados humanos localizados às margens dos oceanos, mares, rios ou lagos e que possuem portos ou atracadouros de embarcações. Face ao movimento de pessoas, chegada e saída de embarcações, muitas vezes com prolongada permanência dos tripulantes e viajantes, aliados ao choque de culturas provoca um aumento de criminalidade;
\end{abstract}

As localidades de fronteira determinam um permanente contato entre dois ou mais povos com culturas e hábitos diferentes, além de interesses diversos que provocam um aumento de criminalidade;

As localidades de população flutuante se caracterizam por suas peculiaridades, fazendo atrair por razões industriais, culturais, comerciais, profissionais ou outros motivos, considerável movimento permanente de pessoas estranhas àquela comunidade, com permanência efêmera, mas com instalações periódicas e renovadas de contingentes humanos que contribuem para o aumento da criminalidade;

As localidades de jogos e diversões, são normalmente área de centro turístico, onde as diversões são contínuas e de grande extensão, principalmente noturnas. Nestes locais existe um fluxo grande de pessoas das mais diversificadas culturas e interesses; $\mathrm{e}$

As localidades de baixa renda per capita determinam também um aumento de criminalidade, pois os mais pobres, provocados pelo desnível social, são levados à inveja e à revolta, conduzindo os mais fracos à delinquência.

Com base nos fatores criminológicos, são acrescidos uma fração de 0,2 policial por fator criminológico identificado no local de atuação. Desta forma, as Unidades, principalmente da região interiorana, teriam um efetivo mais condizente com a sua população e condições sociodemográficas. Vale salientar que a promoção de pesquisas de opinião sobre atuação policial são relevantes, a partir do momento em que podem ser utilizadas como forma de mensuração desempenho de policiais e seus serviços, bem como da qualidade de sua interação com as comunidades, além de auxiliar os gestores na definição de prioridades, a partir das avaliações dos programas de policiamento.

Além disso, cidadãos insatisfeitos com a ação da polícia são menos propícios a acioná-la ou fornecer informações sobre atividades criminosas. Desta forma, percepções negativas sobre a polícia contribuem para a redução da eficiência da própria atuação policial, o que eventualmente pode colaborar para o aumento dos índices de criminalidade. Como as pesquisas têm demonstrado que o medo do crime tem o efeito de influenciar de forma negativa nas avaliações sobre as polícias, é razoável se pensar na existência de um ciclo vicioso que precisa ser quebrado: altas taxas de criminalidade alimentam e são alimentadas pela desconfiança em relação às polícias (OLIVEIRA JÚNIOR, 2011).

\title{
Principais fatores determinantes da percepção de (in)segurança no Brasil: Os dados PNAD (2009) e da Pesquisa de Vitimização da SENASP (2012)
}

A Pesquisa Nacional por Amostra de Domicílios (PNAD) de 2009 consistiu numa investigação suplementar a respeito dos temas Justiça e Vitimização, resultado do trabalho do Instituto Brasileiro de Geografia e Estatística (IBGE), em parceria com o Conselho Nacional de Justiça (CNJ), que teve como objetivo 
Levantamento e análise das principais condicionantes da percepção de segurança na sociedade brasileira e proposta de um modelo de atuação

principal traçar o perfil socioeconômico das vítimas de agressão física, furto e roubo, no período de 27/09/2008 a 26/09/2009, atualizando os índices de referência para análise e compreensão desses fenômenos, em nível nacional, identificando como eles afetam a vida da população brasileira.

Essa pesquisa traçou um perfil socioeconômico das vítimas de roubo, furto, agressão física e tentativa de furto ou roubo, investigando características gerais da população, tais como educação, migração, trabalho, rendimento e habitação, sendo que a última edição desta pesquisa, em nível nacional, havia sido realizada em 1988. Na nova edição, foram incluídas questões que tratavam da percepção de segurança, fato este que merece destaque, haja vista o fato de que a maioria das pesquisas de vitimização realizadas no país não contemplam este aspecto. As informações foram coletadas em três diferentes contextos: o domicílio, o bairro e a cidade e para analisar os condicionantes dessa percepção de (in)segurança foram selecionadas variáveis de naturezas geográfica, social, geográfica e econômica, tais como: idade, sexo, renda, localidade, dentre outras, consideradas fortemente preditoras dos níveis de vitimização.

No Brasil, foram visitados 851 municípios, numa amostra de 399.387 pessoas, com 10 anos ou mais de idade, distribuídas em 153.837 domicílios. Estes resultados foram estatisticamente extrapolados baseados no universo de 162,8 milhões de pessoas. No Estado de Sergipe, a PNAD 2009 foi aplicada em 11 municípios, numa amostra de 6.037 pessoas, com 10 anos ou mais de idade, distribuídas em 2.230 domicílios em todo o país. Os dados foram estatisticamente extrapolados baseados no universo de aproximadamente 1,7 milhões de pessoas.

No suplemento sobre vitimização da PNAD 2009, foram adicionadas questões com o intuito de avaliar a percepção de segurança, no tocante à violência, de pessoas com 10 anos ou mais de idade e esse padrão manteve-se para todos os indivíduos entrevistados. Para efeito deste estudo, serão analisados somente os dados referentes à percepção de segurança e à vitimização referente aos casos de roubo ou furto, sendo, para estes últimos, estabelecido o período dos últimos 365 dias para os entrevistados.

No Brasil, dos 162,8 milhões de pessoas, com 10 anos ou mais de idade, $78,6 \%$ delas sentiam-se seguras no domicílio, $67 \%$ no bairro e $52,8 \%$ no município onde residiam em 2009 . O Estado de Sergipe acompanhou o padrão nacional, sendo constatado, naquele ano, que dos 1,7 milhões de pessoas, na mesma faixa etária, $76,8 \%$ sentiam-se seguras no domicílio, $63,3 \%$ no bairro e $50,4 \%$ na cidade onde residiam. Esses dados permitem constatar o fato de que à medida que os sergipanos se afastam de suas casas a percepção de segurança diminui.

A PNAD 2009 também revelou que, tanto no Brasil quanto em Sergipe, os moradores da zona rural sentem-se mais seguros em seus domicílios, quando comparados aos moradores das cidades. Este fato corrobora com os resultados das pesquisas quantitativas, baseadas em dados do Sistema de informação de Mortalidade do Ministério da Saúde - SIM/DATA/SUS, os quais apontam que a criminalidade violenta se encontra potencialmente concentrada nas zonas urbanas.

Considerando que a cidade foi o ambiente onde foram registrados os maiores níveis de insegurança, a análise das próximas informações terá ênfase neste ambiente de acordo com o gênero, cor ou raça, faixa 
Levantamento e análise das principais condicionantes da percepção de segurança na sociedade brasileira e proposta de um modelo de atuação para a PMSE

SOUZA, J. R. M.; SILVA, C. E.

etária e rendimento mensal domiciliar per capita (salário mínimo). No tocante ao gênero, pode-se afirmar que no Brasil, 55,2\% dos homens sentem-se seguros em suas cidades, enquanto 50,5\% das mulheres sentiamse seguras em 2009. Em Sergipe foi constatado um resultado similar, onde 52,6 dos sergipanos sentem-se seguros nos seus municípios, contra 48,3 das mulheres sergipanas que afirmam sentir-se seguras em suas cidades. Isso revela que o homem sergipano se sente mais seguro que a mulher, considerando-se a mesma faixa etária.

Com relação à cor ou raça, o PNAD apontou que no Brasil, dentre as pessoas que se declararam brancas, $53,3 \%$ sentiam-se seguras em suas cidades, enquanto $52,3 \%$ das pessoas negras ou pardas, sentiamse seguras, nas mesmas condições. Em Sergipe, 50,5\% das pessoas brancas sentem-se seguras em suas cidades, enquanto 50,4\% dos sergipanos que se declararam negros ou pardos sentiam-se seguros em relação à violência nas cidades. No tocante a este quesito, cabe uma análise mais aprofundada.

Ao se observar a distribuição de pessoas que se sentiam seguras nas cidades, no Brasil foram constatados que $49,1 \%$ das pessoas, que se declaram brancas, sentiam-se seguras em suas cidades, enquanto $50,3 \%$ dos que se declaram negros ou pardos sentiam-se seguros nas cidades em que residem. Em Sergipe houve uma grande discrepância, onde $28,1 \%$ dos que se declaram brancos, informaram sentir-se seguros em seus municípios, enquanto $71,6 \%$ declararam-se negros ou pardos e sentiam-se seguros nos municípios sergipanos. Esse dado denota que os sergipanos que se declaram negros ou pardos sentem-se mais seguros nas cidades, quando comparados aos brancos.

Quanto ao quesito faixa etária o PNAD 2009 revelou que, no Brasil, na faixa etária de 10 a 15 anos de idade, $57,9 \%$ dos indivíduos sentiam-se seguros no município, percentual que foi decrescendo até a faixa etária dos 35 aos 49 anos de idade, quando atingiu 50,9\% das pessoas nesta faixa que se sentem seguras em suas cidades. As faixas seguintes, de 50 a 59 anos, de 60 a 69 anos e acima de 70 anos, reiniciaram um movimento de ascensão perfazendo os índices de 51,0\%, 51,9\% e 54,0\% respectivamente. Em Sergipe, o PNAD revelou que a faixa-etária acima dos 70 anos, juntamente com a faixa dos 16 aos 24 anos de idade, compartilham os maiores índices de percepção de segurança nas cidades: 61,1\% e 53,0\%, respectivamente. O registro de menor índice ficou por conta da faixa etárias dos 34 aos 49 anos de idade, de forma similar ao observado no Brasil.

De acordo com a faixa salarial, o indicador adotado foi a renda familiar per capita (salário mínimo). Observou-se que, no Brasil, a percepção de segurança nos municípios era menor nos indivíduos com padrão de rendimento mensal familiar mais elevado. Da população com rendimentos acima de 2 salários mínimos, $46,2 \%$ sentiam-se seguras em suas cidades, enquanto $60,9 \%$ da população que vive com renda per capita familiar, abaixo de 1/4 do salário mínimo, sentiam-se seguras no que tange à violência nas cidades.

O Estado de Sergipe diferiu do padrão seguido pela média nacional pois o menor índice de percepção de segurança ficou por conta da classe dita sem rendimento, seguida pela classe com rendimento mensal acima de 2 salários mínimos que apontaram, 37,9\% e 42,5\%, respectivamente. A maior percepção de segurança entre os sergipanos, no tocante à faixa salarial acompanhou o padrão nacional e ficou por conta 
Levantamento e análise das principais condicionantes da percepção de segurança na sociedade brasileira e proposta de um modelo de atuação

da população que recebe menos de $1 / 4$ de salário mínimo. Os dados obtidos permitem inferir que quanto maior o rendimento mensal familiar per capita, menor a percepção de segurança pelo indivíduo, no âmbito do município.

De acordo com o PNAD 2009, no Brasil, em números absolutos, 11,9 milhões de pessoas foram vítimas de roubo ou furto no Brasil no ano de 2009 . Isto corresponde a um percentual de $7,3 \%$ da população residente. Do quantitativo de vítimas, $54,6 \%$ eram pessoas do sexo masculino e $45,4 \%$ eram mulheres. $48,4 \%$ eram de cor ou raça branca, enquanto $50,6 \%$ se auto declararam de raça preta ou parda. Quanto à faixa etária, a pesquisa revelou que as faixas extremas, ou seja, de 10 a 15 anos de idade e acima de 70 anos, foram as faixas menos atingidas pela violência, com respectivos 5,9\% e 4,2\% de vítimas de roubos ou furtos.

Depreende-se da análise que a violência atinge as pessoas de menor idade e vai crescendo assumindo seu pico na faixa de 35 a 49 anos de idade, quando começa a decrescer até a última faixa etária. Desta forma a violência concentra-se $71,8 \%$ na faixa compreendida entre os 16 e 49 anos de idade. No tocante à violência relacionada com a renda mensal familiar, observou-se que no Brasil, a classe mais atingida recebe entre $1 \mathrm{e}$ 2 salários mínimos, respondendo por $27,4 \%$ enquanto as menos atingidas recebem menos de $1 / 4$ de salário mínimo, per capita, ou mesmo não recebem rendimentos, alcançando-se os percentuais de 5,3\% e 0,9\%, respectivamente.

Em Sergipe, a mesma pesquisa apontou que 9,1\% da população foi vítima de roubo ou furto. Das 155 mil vítimas de roubo ou furto, $61,5 \%$ eram homens, enquanto $38,5 \%$ eram do sexo feminino. $31,9 \%$ eram da cor branca, enquanto $68,1 \%$ declararam-se da cor ou raça preta ou parda. A faixa etária mais suscetível à violência encontrava-se, em 2009, entre os 16 e 24 anos de idade, enquanto as faixas extremas de 10 a 15 anos de idade e as pessoas acima de 70 anos, estariam menos propensas a ser vítimas de roubo ou furto, alcançando $7,7 \%$ e 3,5\%, respectivamente.

Em relação à classe de rendimento mensal per capita, percebeu-se que, para este índice, o Estado de Sergipe acompanhou o padrão nacional, sendo a classe que recebe rendimentos entre 1 e 2 salários mínimos, a mais propensa a ser vítima de roubos ou furtos, respondendo por $26,2 \%$ do total das vítimas de roubo ou furto, enquanto as que recebiam menos de $1 / 4$ de salário mínimo ou mesmo não recebiam rendimentos foram responsáveis pelos menores índices, a saber: $12,1 \%$ e o,4\%, respectivamente.

Desta forma observa-se que o perfil das vítimas sergipanas de roubo ou furto são homens, declarados de cor ou raça preta ou parda, que, em 2009, possuíam entre 16 e 24 anos de idade e recebiam entre $1 / 2$ e 1 salários mínimos mensais, per capita. Estes dados concretos de vitimização contradizem aqueles apresentados na percepção de segurança, visto anteriormente, posto que os homens, de raça ou cor parda, jovens e com salários medianos-baixos atestaram sentir-se mais seguros em seus municípios, o que denota vitimização e percepção de segurança podem assumir caminhos divergentes. 


\section{A Pesquisa de Vitimização da SENASP - 2012}

A pesquisa de vitimização realizada pela SENASP em 2012, publicada nos Estudos sobre vitimização da Secretaria Nacional de Segurança Pública em 2017, inseriu em seu questionário diversos indicadores para avaliar a percepção de insegurança pela população. Os principais são: Sentimento de insegurança (de dia, de noite, em casa, no trabalho, no bairro, na cidade, etc.); Comportamento (mudar de caminho, evitar sair e frequentar determinados locais, etc.); Medo de ser vítima de crimes no bairro (furto, assalto, roubo, agressão física, sexual, etc.); Medo de ser vítima de violência doméstica; Avaliação retrospectiva da segurança (no bairro, na cidade); Temor de ser vítima de crimes, de um modo geral (assalto, furto, roubo, agressão física, sexual, etc.); e Probabilidade de vitimização (assalto, furto, roubo, agressão física, sexual, etc.).

Percebe-se que a insegurança, como outros fenômenos sociais complexos, apresenta várias dimensões - cognitiva, afetiva, comportamental, dentre outras, sendo os indicadores modelados no intuito de tentar capturar o fenômeno em suas várias dimensões. Eles aferem aspectos diferentes da insegurança, tais como: preocupação com o tema na sociedade, conhecimento sobre o problema, o medo pessoal, comportamentos adotados ou modificados. Desta forma, existem nuances que devem ser exploradas para que se possa compreender o problema em sua integralidade. 0 quadro 1 ajuda a diferenciar estas dimensões.

Quadro 1: Tipos de resposta com relação à insegurança.

\begin{tabular}{|c|c|c|c|}
\hline \multirow{2}{*}{$\begin{array}{l}\text { Modo de } \\
\text { resposta }\end{array}$} & \multicolumn{3}{|c|}{ Categoria de resposta face ao objeto de atitude } \\
\hline & AFETIVA & & COMPORTAMENTAL \\
\hline VERBAL & $\begin{array}{l}\text { Expressões de } \\
\text { sentimentos }\end{array}$ & Expressões de crenças & Expressões de intenções comportamentais \\
\hline $\begin{array}{l}\text { Conceitos } \\
\text { Associados }\end{array}$ & Temor ao delito & $\begin{array}{l}\text { Resposta punitivas; Percepção de risco de } \\
\text { vitimização; preocupação securitária. }\end{array}$ & $\begin{array}{l}\text { Estratégia de evitação e proteção; Ações sociais, } \\
\text { econômicas e políticas. }\end{array}$ \\
\hline Exemplos & $\begin{array}{l}\text { Declarações de temor, } \\
\text { fobia, raiva, compaixão, } \\
\text { face aos delinquentes }\end{array}$ & $\begin{array}{l}\text { Declarações sobre como se deve tratar os } \\
\text { delinquentes, como se deve castigá-los, o } \\
\text { que se deve fazer com a delinquência, } \\
\text { quais são suas causas e efeitos, como } \\
\text { evoluiu, etc. }\end{array}$ & $\begin{array}{l}\text { Declarações de disposições face aos delinquentes, por } \\
\text { exemplo, uso de armas para a defesa ou vingança, a } \\
\text { nível individual, ou linchamentos e protestos, ao nível } \\
\text { coletivo; declarar medidas de autoproteção }\end{array}$ \\
\hline NO VERBAL & Respostas fisiológicas & Respostas perceptivas & Respostas de comportamento \\
\hline Exemplos & $\begin{array}{l}\text { Sentir temor, fobia, } \\
\text { raiva, compaixão, face } \\
\text { aos delinquentes. }\end{array}$ & $\begin{array}{l}\text { Perceber e crer nas causas da } \\
\text { delinquência e nas medidas; crer na pena } \\
\text { de morte, etc. }\end{array}$ & $\begin{array}{l}\text { Ações concretas como evitar zonas e pessoas, } \\
\text { comprar armas para a defesa, assinar petições, ou } \\
\text { participar de protestos, linchamentos, etc. }\end{array}$ \\
\hline
\end{tabular}

Fonte: AJZEN (1988, citado por MANSTED et al., 1966, citado por OTAMENDI, 2015).

Os Estudos sobre vitimização e violência culminaram numa série de índices que apontaram para os riscos de vitimização, de acordo com os tipos criminais relacionados à pessoa, os quais foram dispostos de forma organizada na Tabela 1, de modo que os dados referentes ao estado de Sergipe pudessem ser comparados, não só à média nacional, como também ao maior e ao menor índice observados, de acordo com a Unidade da Federação.

Tabela 1: Índices de risco de vitimização por crime contra a pessoa.

\begin{tabular}{|c|c|c|c|c|c|c|}
\hline \multirow[b]{2}{*}{ RISCO DE VITIMIZAÇÃO POR } & \multirow[b]{2}{*}{$\begin{array}{l}\text { R-Méd } \\
\text { Brasil }\end{array}$} & \multicolumn{2}{|c|}{ Maior índice } & \multicolumn{2}{|c|}{ Menor índice } & \multirow[b]{2}{*}{ Sergipe } \\
\hline & & UF & índice & UF & índice & \\
\hline Ofensa verbal entre indivíduos mais velhos e mais jovens & 1,95 & $\mathrm{AC}$ & 3,15 & MS & 1,10 & 1,63 \\
\hline Ameaça com arma de fogo ou arma branca entre indivíduos negros e brancos & 1,01 & MS & 9,15 & SC & 0,25 & 1,25 \\
\hline Ameaça com arma de fogo ou arma branca entre homens e mulheres & 1,66 & CE & 3,08 & GO & 0,75 & 1,23 \\
\hline Discriminação por raça/cor entre indivíduos negros e brancos & 5,03 & MS & 39,41 & $\mathrm{PI}$ & 0,72 & 3,74 \\
\hline Ofensa sexual entre indivíduos negros e brancos & 0,88 & MS & 5,28 & TO & 0,16 & 1,40 \\
\hline Ofensa sexual entre mulheres e homens & 4,46 & ES & 8,73 & RR & 1,03 & 5,04 \\
\hline
\end{tabular}


Levantamento e análise das principais condicionantes da percepção de segurança na sociedade brasileira e proposta de um modelo de atuação

\begin{tabular}{|l|c|c|c|c|c|c|}
\hline Agressão física provocada por policial militar entre homens e mulheres & 4,09 & $\mathrm{SE}$ & 14,11 & $\mathrm{MA}$ & 2,03 & 14,11 \\
\hline Insulto provocado por policial militar entre indivíduos negros e brancos & 1,03 & $\mathrm{MS}$ & 5,57 & $\mathrm{MG}$ & 0,6 & 4,44 \\
\hline
\end{tabular}

Fonte: Adaptado de Brasil (2017).

\section{Políticas de Segurança Pública}

Antes de discorrer sobre esse tema, faz-se necessário distinguir os conceitos: políticas públicas de segurança e políticas de segurança pública. Na visão de Oliveira (2002), "políticas públicas de segurança é expressão que engloba as diversas ações, governamentais e não governamentais, que sofrem impacto ou causam impacto no problema da criminalidade e da violência". Já a política de segurança pública seria a "expressão referente às atividades tipicamente policiais" ou à "atuação policial 'strictu sensu'". Cerqueira et al. (2018) alerta que, quando os cidadãos perdem a esperança no futuro, quando o medo passa a reinar, perde-se a crença nas instituições do Estado e as pessoas passam a confinar-se em suas casas e condomínios, evitando o uso de espaços públicos.

Outro ponto interessante nesse estudo, revela o equívoco cometido, de forma recorrente, por muitas autoridades na área de segurança pública que confundem a produção de segurança pública com a produção de atividade do trabalho policial, momento em que o meio passa a tornar-se o fim, em si mesmo. Assim, é dado um enfoque ao número de abordagens policiais ou mesmo apreensão de drogas, por exemplo, que, muitas vezes, podem não ter efeito algum na produção efetiva de segurança, podendo, inclusive, concorrer no sentido contrário, aumentando o número de mortes violentas, balas perdidas e o medo junto à população.

Ocorre que toda a confusão referente à produção do trabalho policial e à produção de segurança pública termina gerando um direcionamento da responsabilidade às organizações policiais. Desse modo, quando surgem problemas relacionados à segurança pública, toda a responsabilidade recai sobre as polícias, ficando isentos de responsabilidade os governos que, muitas vezes, não desenvolvem um planejamento adequado e preventivo, dentro de uma política de Estado.

Na visão de Soares (2006), existem duas linhas de ação complementares para atuar na promoção da segurança pública: a primeira, através de políticas preventivas e a segunda, por meio da ação das Polícias, nos Estados, ou Guardas municipais, no âmbito dos municípios. Neste contexto, as políticas de prevenção da criminalidade violenta podem produzir efeitos rapidamente, a baixo custo, se considerarmos os municípios e seus governos, pois, devido à sua capilaridade, agilidade e proximidade com a linha de frente, constituem a forma mais adequada à execução de políticas preventivas.

Soares (2006) complementa que políticas que tem por objetivo prevenir a violência criminal não são políticas estruturais, de longo prazo, destinadas a atuar sobre as macroestruturas socioeconômicas do país e, pensar dessa forma, seria incorrer em dois erros: O primeiro por induzir à ideia do "imobilismo", ou seja, enquanto não se pôr fim aos problemas estruturais da sociedade brasileira, nada poder-se-ia fazer para conter a insegurança; em segundo lugar, ao se negar a possibilidade de soluções no curto prazo, induz à população à frustração e desespero, sentimentos propícios ao surgimento de propostas autoritárias como: armar a população, erguer muros mais altos, trocar a segurança pública por soluções privadas, apoiar a 
Levantamento e análise das principais condicionantes da percepção de segurança na sociedade brasileira e proposta de um modelo de atuação para a PMSE

violência policial, instaurar a pena de morte, reduzir a idade de imputabilidade penal, dentre outras opções que só terminam por realimentar o ciclo perverso da violência.

Cerqueira et al. (2018) analisou as experiências internacionais e nacionais que demonstram ser possível reduzir a taxa de homicídios num curto espaço de tempo, a exemplo de Nova York, Medellín, Ciudad Juárez, Pernambuco (do Pacto pela Vida), Espírito Santo (do Estado Presente) e da Paraíba pela Paz, conseguiu enxergar padrões nestes modelos, os definindo como uma espécie de "ingredientes" para se conseguir bons resultados, os quais encontram-se relacionados no quadro 2 .

Quadro 2: Os sete elementos para a segurança efetiva.

\begin{tabular}{|c|c|c|}
\hline Fator & Ator & Ações \\
\hline Comprometimento do poder político. & $\begin{array}{l}\text { Presidente, } \\
\text { Governador e } \\
\text { Prefeito. }\end{array}$ & $\begin{array}{l}\text { Políticas efetivas envolvem processos de mobilizar e articular os inúmeros } \\
\text { atores sociais, bem como coordenar as ações intersetoriais. }\end{array}$ \\
\hline $\begin{array}{l}\text { Mobilização e articulação de todos os } \\
\text { atores na busca pela paz. }\end{array}$ & $\begin{array}{l}\text { Presidente, } \\
\text { Governador e } \\
\text { Prefeito. }\end{array}$ & $\begin{array}{l}\text { Mobilizar comunidades, academia, organizações civis, empresários, igrejas e as } \\
\text { diversas agências do Estado. }\end{array}$ \\
\hline $\begin{array}{l}\text { Organização e gestão da segurança } \\
\text { pública com base no método } \\
\text { científico e nas evidências empíricas. }\end{array}$ & $\begin{array}{l}\text { Cúpula da } \\
\text { Segurança Pública. }\end{array}$ & $\begin{array}{l}\text { Gerir com base em dados precisos e diagnósticos locais das dinâmicas criminais } \\
\text { e sociais, planejar com ações de curto, médio e longo prazos, além de monitorar } \\
\text { e avaliar o impacto para saber se as ações adotadas atingiram o objetivo } \\
\text { almejado. }\end{array}$ \\
\hline $\begin{array}{l}\text { Controle e retirada das armas de fogo } \\
\text { e de munições de circulação. }\end{array}$ & $\begin{array}{l}\text { Exército Brasileiro } \\
\text { e Organizações } \\
\text { policiais }\end{array}$ & $\begin{array}{l}\text { Empreender ações que afetem o fluxo de armas e munições, através da } \\
\text { legislação pertinente, como o Estatuto do Desarmamento, aliados ao trabalho } \\
\text { de inteligência e investigação, identificando canais responsáveis pela entrada de } \\
\text { armas ilegalmente no país. }\end{array}$ \\
\hline $\begin{array}{l}\text { Expansão de espaços destinados à } \\
\text { mediação de conflitos }\end{array}$ & $\begin{array}{l}\text { Sociedade em } \\
\text { geral. }\end{array}$ & $\begin{array}{l}\text { Fomentar o diálogo em detrimento da violência como instrumento de solução } \\
\text { das contendas, a exemplo da aplicação dos princípios de Justiça Restaurativa. }\end{array}$ \\
\hline $\begin{array}{l}\text { mudança do modelo de polícia, de } \\
\text { uma abordagem meramente reativa, } \\
\text { para um modelo de repressão } \\
\text { qualificada }\end{array}$ & $\begin{array}{l}\text { Cúpula da } \\
\text { Segurança pública. }\end{array}$ & $\begin{array}{l}\text { Definir prioridades e orientá-las, estrategicamente, ao trabalho policial, } \\
\text { alinhando aos serviços de inteligência, de forma a inverter o eixo de prisões de } \\
\text { baixa qualidade, a partir do policiamento ostensivo, para retirada de circulação } \\
\text { dos homicidas contumazes e facções criminosas que geram mais medo e dano à } \\
\text { sociedade. }\end{array}$ \\
\hline
\end{tabular}

Fonte: Cerqueira et al. (2018).

Diante da problemática observada, em contexto nacional, e com base nas contribuições dos autores envolvidos na presente pesquisa foi construída uma matriz SWOT, ferramenta que permite traçar diagnósticos estratégicos de uma Corporação, no caso em tela, a Polícia Militar do Estado de Sergipe, no meio em que está implantada, de forma a facilitar a visualização das forças, fraquezas, oportunidade e ameaças, para, a partir daí, vislumbrar um cenário possível de políticas de segurança pública voltadas para o policiamento Ostensivo, no intuito de melhorar a percepção de segurança junto à sociedade sergipana.

Diante das informações extraídas da Matriz Swot da PMSE que revelam: suas Forças, muitas das quais precisam ser reafirmados em ações de continuidade; Fraquezas, que constituem questões internas as quais carecem de atuação específica para que possam ser transformadas em forças; Oportunidades, quesitos que podem ser explorados pela Instituição com vistas a transforma-se em diferencial competitivo; e Ameaças, que embora não representem perigo atual, apresentam grande potencial causar danos e merecem uma atenção mais focada, foram traçadas linhas de ação com base nos conceitos apresentados pelos autores, bem como os dados extraídos do material que serviu de base para a construção do presente artigo e serão dispostas. 
Quadro 3: Matriz SWOT da PMSE.

\begin{tabular}{|c|c|c|}
\hline & Forças (Strengths) & Fraquezas (Weaknesses) \\
\hline 1 & 1. Capilaridade & 1.Efetivo reduzido \\
\hline $\mathrm{N}$ & 2. Termo Circunstanciado de Ocorrência & 2. Carência de pesquisas de Satisfação \\
\hline $\mathrm{T}$ & 3. Atividades de Inteligência & 3.Ausência de cursos de capacitação contínuos \\
\hline $\mathrm{E}$ & 4. Exigência de qualificação para o ingresso & 4. Policiamento Comunitário \\
\hline $\mathrm{R}$ & 5. Sistema de Comunicação eficiente & 5.Ausência de normatização de procedimentos \\
\hline $\mathrm{N}$ & 6. Hierarquia e disciplina & 6. Estruturas físicas precárias \\
\hline $\begin{array}{l}\text { A } \\
S\end{array}$ & $\begin{array}{l}\text { 7. Divulgação das ações positivas, operacionais e administrativas, } \\
\text { através do Site da Instituição. }\end{array}$ & 7.Carência de incentivos à capacitação \\
\hline \multirow{10}{*}{$\begin{array}{l}E \\
X \\
T \\
E \\
R \\
N \\
A \\
S\end{array}$} & Oportunidades (Opportunities) & Ameaças (Threats) \\
\hline & 1. Ciclo completo de polícia & 1. Segurança privada \\
\hline & 2.Videomonitoramento & 2. Crescimento dos índices de violência \\
\hline & 3. Novas tecnologias de integração & 3. Instalação de facções criminosas \\
\hline & 4. Concurso para Polícia Administrativa & 4. Legislações antigas e ultrapassadas \\
\hline & 5. Convênios com Instituições de Ensino & 5.Pauta negativa da mídia às ações policiais \\
\hline & 6. Convênios com os municípios & 6. Deficiência na área de TI \\
\hline & 7. Gestão de colégios públicos através de militares oriundos da & \\
\hline & reserva & \\
\hline & $\begin{array}{l}\text { 8. Criação de canais de comunicação diretos com a comunidade, } \\
\text { através de aplicativos de celular e participação nas mais diversas redes } \\
\text { sociais }\end{array}$ & \\
\hline
\end{tabular}

\section{Políticas externas à Corporação PMSE: Propositura de PEC}

Propositura de PEC, com apoio dos Governadores do Estado, propor a 'desconstitucionalização das polícias', de forma a permitir a transferência aos Estados, do poder para decidirem, em suas Constituições Estaduais, qual o modelo de polícia que desejam adotar sendo facultado, inclusive, a preservação do modelo atual.

\section{Políticas de prevenção ao crime, com foco na criança e adolescente}

Implementação, no Estado de Sergipe, por deliberação do governo do Estado, da gestão de Escolas públicas por militares, em sua maior parte da reserva, no intuito de transmitir noções de moral, civismo e disciplina, dentre outros preceitos militares. Além de atuar diretamente na raiz do problema, ou seja, nas crianças adolescentes, principais alvos do tráfico e do crime de uma forma geral, está inciativa trará novas perspectivas de futuro àqueles que, muitas vezes, carecem de opções a seguir em suas vidas. Além disso, a proximidade com os alunos possibilitará uma maior aproximação com a comunidade, repercutindo na familiarização com a presença policial, estimulando a confiança e melhorando a percepção de segurança junto à comunidade.

\section{Políticas internas à Corporação PMSE: Atividades de fomento ao Policiamento comunitário}

Fortalecer e fomentar a cultura do Policiamento Comunitário através dos veículos tipo 'Motor Casas', ou Bases móveis. Através desses veículos que, na prática, funcionarão como pequenos destacamentos móveis, conseguir-se-á uma maior mobilidade urbana, alcançando locais distantes do poder público, promovendo um caráter mais dinâmico às ações de policiamento e aproximando-se cada vez mais do cidadão. Com a possibilidade de utilização dos links de videomonitoramento nesses veículos, torna-se possível um acompanhamento mais eficiente da área policiada, através de parcerias com a iniciativa privada 
Levantamento e análise das principais condicionantes da percepção de segurança na sociedade brasileira e proposta de um modelo de atuação para a PMSE

no sentido de espalhar câmeras em diversos pontos do comércio, bem como áreas residências, de forma a coibir as ações criminosas.

\section{Fomento às atividades de inteligência}

Considerando-se que a maior parte dos danos causados à sociedade, no que tange à percepção da segurança, tem origem em ações criminosas mais complexas, a exemplo do tráfico de armas, de drogas e os homicídios e, aproveitando-se da capilaridade, característica da Polícia Militar, faz-se necessário o investimento em iniciativas de fortalecimento às atividades de inteligência pois, a partir delas, será possível ações mais efetivas no sentido de tirar de circulação homicidas e traficantes costumazes, culminando na redução dos índices de criminalidade, promovendo melhorias na percepção de segurança por parte da população.

\section{Fortalecimento na confecção dos Termos Circunstanciados de Ocorrência}

A atuação da Polícia Militar na confecção dos termos circunstanciados, em razão dos delitos de menor potencial ofensivo, promove, junto à comunidade, uma maior sensação de justiça, gerando também economia de meios, bem como reduzindo os tempos gastos em ocorrências. Tudo isso traduz-se em um maior período de permanecia das viaturas nas ruas, culminando numa maior ostensividade e aumentando a percepção de segurança por parte da população, além de reduzir os índices de criminalidade.

\section{Utilização de tecnologias e sistemas integrados com outras forças e agências}

A adesão ao uso de sistemas, a exemplo da plataforma SINESP, disponibilizados pelo Governo Federal, sob a proposta da integração nacional de dados e informações, promoverá avanços no tocante à implementação de um banco de dados estatísticos que será utilizado para uma melhor alocação dos recursos disponíveis, de acordo com as áreas de maior probabilidade de incidência de ocorrências, contribuindo para que a Polícia Militar faça-se presente nos locais onde exista uma maior demanda, culminando numa melhor percepção de segurança, junto à comunidade.

\section{Fomento e incentivo às atividades voltadas à educação e capacitação do efetivo}

O que não pode ser medido, não pode ser gerenciado. Desta forma, faz-se necessário a adoção de indicadores de desempenho para as atividades de polícia, com vistas a nortear as ações a serem desenvolvidas. Para isso, é necessário que todos os processos adotados pela Polícia Militar estejam explícitos em protocolos de procedimento operacional padrão (POP) de forma que, em parceria com os órgãos de fiscalização da atividade policial, seja possível estabelecer procedimentos protocolares validados, diante da legislação vigente. Os convênios com Instituições de ensino promoverão um maior contato dos militares com o ambiente acadêmico que, juntos debruçar-se-ão diante de temas relacionados ao contexto de segurança pública, que consiste num dever do Estado, mas uma obrigação de todos. 
Levantamento e análise das principais condicionantes da percepção de segurança na sociedade brasileira e proposta de um modelo de atuação para a PMSE

\section{Capacitação do efetivo disponível}

Promoção de concurso público para Polícia Administrativa: através dessa iniciativa será possível alocar um quantitativo maior de militares na atividade fim, promovendo uma economia de meios. Essa iniciativa também ameniza o problema de efetivo reduzido, muito comum em diversas Corporações que, aliado à fixação no terreno, com base nas técnicas de lotação de acordo com a população local, através do cálculo pelo método americano, proporcionará uma disposição mais equilibrada da tropa no terreno.

Resolvido o problema do quantitativo, o próximo passo será o fomento à capacitação. Observa-se que, devido às novas exigências de ingresso para a carreira policial, o militar já ingressa às fileiras com uma visão diferenciada, tendo plena visão da realidade em que vive e do papel que desempenhará junto à sociedade. Porém, as novas competências que ele deverá obter exigem treinamento constante e contínuo ao longo de sua carreira. Desta forma, faz-se necessário a inclusão de, no mínimo, um ciclo de capacitação bienal de forma que, com a atualização constante dos conhecimentos, possa dispensar um serviço de melhor qualidade junto à sociedade.

\section{Pesquisas de Satisfação e criação de canais diretos com a comunidade}

Para que se possa ter um norte quanto às ações a serem implementadas, faz-se necessário um retorno da sociedade que pode vir através de pesquisas de satisfação que mostrarão a percepção da sociedade quanto à atuação da Polícia Militar. A criação de canais diretos com a população também representa um grande avanço no processo de interação social no sentido de modernizar os meios de denúncia de fatos criminosos, permitindo o acesso virtual da população aos sites policiais.

Isso pode ocorrer través de terminais virtuais espalhados por toda a cidade; de aplicativos smartphones ou sites autoexplicativos e de utilização intuitiva, que permitam que os registros de boletins de ocorrência on line sejam mais detalhados quanto às condições em que ocorreram os crimes, discriminando, obrigatoriamente, dia, hora ou período do dia, local preciso com mapeamento etc.. Assim, tanto a população vitimada seria beneficiada pela acessibilidade a uma delegacia virtual, como também, a polícia passaria a ter um importante instrumento de incremento aos registros, o que também contribuiria para a redução das subnotificações.

\section{CONCLUSÕES}

De tudo o que foi visto, e diante da complexidade do tema, percebe-se que a base para a sustentabilidade das condições de segurança pública, no longo prazo, depende de uma soma de esforços de todos os atores envolvidos. Neste contexto, escolas, igrejas, entidades governamentais precisam somar-se no sentido de buscar a melhor forma no sentido de reduzir os índices de criminalidade e, assim, contribuir para uma maior sensação de segurança. À Polícia Militar cabe envidar esforços no sentido de buscar ações mais efetivas no combate ao crime especializado, devido à sua capilaridade que the permite ocupar todos os municípios do Estado; Cabe também atuar, com foco nos condicionantes elencados, de modo promover 
Levantamento e análise das principais condicionantes da percepção de segurança na sociedade brasileira e proposta de um modelo de atuação para a PMSE

ações específicas de acordo com as informações que lhes são apresentadas. Porém, todos os esforços serão em vão se não buscar 'reinventar-se' de modo a poder agir direto nas causas do problema.

Caso não se implementem políticas públicas inteligentes, intersetoriais e sensíveis às especificidades de cada região, que sejam capazes de interceptar as microdinâmicas geradoras do crime, mesmo diante dos atuais indicadores de pobreza, desigualdade, falta de educação, qualidade de vida degradada e precariedade no acesso aos direitos, o que os coloca em condições de vulnerabilidade e invisibilidade social, as consequências não fugirão ao agravamento do atual quadro de violência criminal, hora instaurado.

\section{REFERÊNCIAS}

AZEVEDO, M. A.. Concepções sobre criminalidade e modelos de policiamento. Psicologia: Ciência e Profissão, Brasília, v.23, n.3, p.18-25, 2003

BEATO, C.; PEIXOTO, B.; ANDRADE, M. V.. Crime, oportunidade e vitimização. Revista Brasileira de Ciências Sociais, v.19, n.55, p.73-89, 2004

BRASIL. Ministério da Justiça e Segurança Pública. Secretaria Nacional de Segurança Pública. Estudos sobre vitimização. Brasília: Secretaria Nacional de Segurança Pública, 2017.

BRETAS, M. L.. Ordem na cidade: o exercício cotidiano da autoridade policial no Rio de Janeiro: 1907-1930. Rio de Janeiro: Rocco, 1997.

CARTENS, P. S. L.; PERIOTTO, A. J.. Efetivo policial militar: paradigmas e proposta metodológica para cálculo de necessidades. Cascavel: EDUNIOESTE, 2010.

CATAO, Y.. Pesquisas de vitimização: notas metodológicas. Anuário do Fórum Brasileiro de Segurança Pública, São Paulo, 2008

CERQUEIRA, D. R. C.. Mapa de homicídios ocultos no Brasil. Brasília: IPEA, 2013.

CERQUEIRA, D. R. C.; LIMA, R. S.; BUENO, S.; NEME, C. FERREIRA, H.; COELHO, D.; ALVES, P. P.; PINHEIRO, M.; ASTOLFI, R.; MARQUES, D.; REIS, M.; MERIAN, F.. Atlas da violência 2018. Brasília: IPEA, 2018.

CHESNAIS, J. C.. A violência no Brasil: causas e recomendações políticas para a sua prevenção. Ciência \& Saúde Coletiva, v.4, p.53-69, 1999.

CONFORTO, L. A.. Administração de Polícia Ostensiva. Cuiabá: 1998.

DANTAS, G. F. L.; PERSIJN, A.; SILVA JÚNIOR, A. P.. O medo do crime. $O$ alferes, v.22, n.62, 2007.

FERREIRA, E. T.; DAMÁZIO, I. N.; AGUIAR, J. M.. Fatores estimuladores da sensação de insegurança e a valorização midiática. Ordem Pública, v.4, n.1, p.121-130, 2011.

FONTOURA, N. O.; RIVERO, P. S.; RODRIGUES, R. I.. Segurança Pública na Constituição Federal de 1988: continuidades e perspectivas. Brasília: IPEA, 2009.
FRAGA, T. L.. Qual o impacto do crime para as vítimas? Uma análise considerando a influência dos roubos e furtos na percepção de segurança e migração no Brasil. Tese (Doutorado) - Universidade Federal de Viçosa, Viçosa, 2015.

HIPÓLITO, M. M.; TASCA, J. E.. Superando o mito do espantalho: uma polícia orientada para a resolução dos problemas de segurança pública. Florianópolis: Insular, 2012.

IBGE. Instituto Brasileiro de Geografia e Estatística. Pesquisa nacional por amostra de domicílios - PNAD: características da vitimização e do acesso à justiça no Brasil - 2009. Rio de Janeiro: IBGE, 2010.

JOÃO G. R.. Segurança Pública e Comunidade. Porto Alegre: 2009.

LIMA NETO, J. S.; VIEIRA, T. A.. A estratégia de prevenção do crime através do desenho urbano. Ordem Pública, v.7, n.1, p.55-77, 2014

OLIVEIRA JÚNIOR, A.. Dá pra confiar nas polícias? Confiança e percepção social da polícia no Brasil. Revista Brasileira de Segurança Pública, São Paulo, v.5, n.9, 2011.

OLIVEIRA, A. S. S.. Políticas de Segurança e Políticas de Segurança Pública: da teoria à prática. São Paulo: 2002.

OTAMENDI, A.. Las reacciones sociales hacia la inseguridad en América Latina: definiciones, indicadores y datos de la última década. Cartografías Del Sur: Revista De Ciencias, Artes Y Tecnología, n.1, 2015. DOI: https://doi.org/10.35428/cds.v0i1.3

SOARES, G. A. D.. O sentimento de insegurança: teorias, hipóteses e dados. In: DUARTE, M. S. B.; PINTO, A. S. CAMPAGNAC, V.. Pesquisa de condições de vida e vitimização de 2007. Rio de Janeiro: Rio Segurança, 2008.

SOARES, L. E.. Novas políticas de segurança pública. Estudos Avançados, São Paulo, v.17, n.47, p.75-96, 2003.

VILARDI, R. G.. Redução da Insegurança Pública: Políticas Pública de Segurança ou Política de Segurança Pública: Estudo de Caso. Tese (Doutorado) - Universidade de São Paulo, São Paulo, 2010.

A CBPC - Companhia Brasileira de Produção Científica (CNPJ: 11.221.422/0001-03) detém os direitos materiais desta publicação. Os direitos referem-se à publicação do trabalho em qualquer parte do mundo, incluindo os direitos às renovações, expansões e disseminações da contribuição, bem como outros direitos subsidiários. Todos os trabalhos publicados eletronicamente poderão posteriormente ser publicados em coletâneas impressas sob coordenação da Sustenere Publishing da Companhia Brasileira de Produção Científica e seus parceiros autorizados. Os (as) autores (as) preservam os direitos autorais, mas não têm permissão para a publicação da contribuição em outro meio, impresso ou digital, em português ou em tradução. 